\title{
Hubungan Kejadian Anemia Dengan Prestasi Belajar Siswi Di SMP Unggulan Bina Insani
}

\section{The Association Between Anaemia Incident and Student Learning Achievement At Bina Insani Junior High School}

\author{
Pratiwi Retno Ayu Dumilah* ${ }^{1}$, Sri Sumarmi ${ }^{2}$
}

\begin{abstract}
ABSTRAK
Latar Belakang: Anemia merupakan salah satu masalah gizi yang masih terjadi di masyarakat. Remaja khususnya remaja putri merupakan salah satu kelompok yang rentan menderita anemia. Penyebab anemia pada remaja diantaranya asupan zat gizi yang rendah terutama zat besi, pola menstruasi, infeksi cacing, penyakit malaria, genetik, dan lainnya. Anemia pada remaja menyebabkan penurunan tingkat kebugaran, daya imun, daya ingat, dan daya konsentrasi yang berdampak pada kemampuan belajar menurun dan akan mempengaruhi prestasi belajar remaja.

Tujuan: Tujuan penelitian ini adalah menganalisis hubungan antara anemia dengan prestasi belajar siswi di SMP Unggulan Bina Insani.

Metode: Desain yang digunakan pada penelitian ini adalah cross sectional dengan sampel sebesar 56 siswi. Pengumpulan data dilakukan dengan wawancara menggunakan kuesioner untuk mendapatkan data karakteristik orang tua, siswi dan pola menstruasi. Kadar $\mathrm{Hb}$ diperoleh dari pengambilan darah pada pembuluh darah vena, kemudian dianalisis dengan metode cyanmethemoglobin. Rata-rata jumlah nilai lima mata pelajaran selama dua semester. Uji statistik yang digunakan adalah chi square dan korelasi eta.

Hasil: Hasil penelitian menunjukkan siswi yang menderita anemia sebanyak $21,4 \%$. Sebagian besar siswi memiliki lama menstruasi normal, siklus yang teratur, dan memasuki masa menstruasi pada usia $\geq 12$ tahun. Terdapat hubungan antara lama menstruasi dengan anemia $(p=0,046)$. Hasil penelitian juga menunjukkan adanya hubungan anemia dengan prestasi belajar siswi $(p=0,026)$.

Kesimpulan: Kejadian anemia yang dialami oleh siswi mempengaruhi prestasi belajar yang diperoleh sehingga disarankan pada siswi untuk memperhatikan makanan yang dikonsumsi dan konsumsi TTD yang diberikan oleh Puskesmas.
\end{abstract}

Kata kunci: anemia, pola menstruasi, prestasi belajar 


\begin{abstract}
Background: Anaemia is one of the nutritional problems that still occur in the community. Teenagers especially adolescent girls are one of the groups who are susceptible to anaemia. The causes of anaemia in adolescents include low intake of nutrients especially iron, menstrual patterns, worm infections, malaria, genetic diseases, and others. Anaemia in adolescents causes decreased levels of fitness, immune power, memory, and concentration power that impact on decreased learning ability and will affect adolescent learning achievement.

Objectives: The purpose of this study was to analyze the relationship between anaemia with student achievement in Unggulan Bina Insani Junior High School.

Methods: The design used in this study was cross sectional with a sample size of 56 female students. Data collection was done by interview using questionnaires to obtain data characteristic of parents, students and menstruation pattern. $\mathrm{Hb}$ levels obtained from blood collection in veins, then analyzed by cyanmethemoglobin method. Average number of grades of five subjects for two semesters. The statistical test used were chi square and eta correlation.

Results: The results showed students who suffered anaemia as much as $21.4 \%$. Most of the girls had normal menstrual periods, regular cycles, and ented menstrual periods at the age of $\geq 12$ years. There was a relationship between menstrual pattern with anaemia $(p=0.046)$. The results also showed an anaemia relationship with students learning achievement $(p=0,026)$.

Conclusion: The occurrence of anaemia experienced by students affects the learning achievement obtained so it is advisable for students to pay attention to the food consumed and the consumption of tablet add blood provided by the Center for Public Health.
\end{abstract}

Keywords: anaemia, menstrual pattern, learning achievement

\footnotetext{
*Koresponden:

ayudumilah99@gmail.com

${ }^{1}$ Departemen Keselamatan dan Kesehatan Kerja

${ }^{2}$ Departemen Gizi Kesehatan,

Fakultas Kesehatan Masyarakat-Universitas Airlangga PENDAHULUAN
}

Remaja adalah aset bangsa dan sumber daya manusia (SDM) yang harus memiliki kualitas baik, disiapkan untuk dapat menghadapi perubahan dan kemajuan teknologi guna memajukan bangsa dan negara. ${ }^{1}$ Remaja merupakan salah satu kelompok yang rentan menderita anemia karena keunikan gaya hidupnya, terutama remaja putri. ${ }^{2}$ Remaja putri lebih berisiko menderita anemia daripada remaja putra. ${ }^{3} \mathrm{Hal}$ tersebut disebabkan karena pola makan yang kurang tepat untuk menjaga penampilannya, pemahaman gizi yang keliru, kesukaan berlebihan terhdap makanan tertentu, menstruasi yang dialami setiap bulan. ${ }^{3}$ Remaja merupakan salah satu kelompok yang rentan menderita anemia, terutama remaja putri. Remaja yang menderita anemia akan mengalami terhambatnya proses tumbuh, motorik, mental dan kecerdasan serta penurunan tingkat kebugaran, daya ingat, daya imun dan daya konsentrasi sehingga berdampak pada kemampuan belajar rendah dan berpengaruh pada prestasi belajar. ${ }^{3,4}$

Anemia pada remaja ditandai dengan kadar hemoglobin $(\mathrm{Hb})<12 \mathrm{~g} / \mathrm{dl}$. Prevalensi anemia di Indonesia mencapai $21,7 \%$ pada tahun 2013. Prevalensi anemia pada perempuan mencapai 23,9\%. Menurut kelompok umur prevalensi anemia umur 5-14 tahun sebesar 26,4\% dan umur 15-24 tahun sebesar $18,4 \% .^{5}$ Prevalensi anemia pada wanita usia subur di pondok pesantren beberapa kabupaten di Jawa Timur mencapai $38,2 \%$ tahun $2006 .{ }^{6}$ Di kota Surabaya anemia pada remaja SMP dan SMA mencapai $26,5 \%{ }^{7}$ Penelitian Setyono (2010) menunjukkan 
anemia pada remaja putri di Surabaya mencapai 33,3\%. ${ }^{8}$

Anemia pada remaja disebabkan oleh beberapa faktor diantaranya perdarahan hebat dan menstruasi setiap bulan, kurangnya kadar zat besi dalam tubuh, kekurangan asam folat, vitamin B12, penyakit kronis, penyakit malaria, infeksi cacing tambang, keturunan atau genetik. ${ }^{3,9,10}$ Anemia yang sering ditemukan adalah karena kekurangan atau defisiensi zat besi. ${ }^{3}$ Defisiensi zat besi salah satunya disebabkan karena menstruasi setiap bulan. Menstruasi menyebabkan remaja putri kehilangan darah $\pm 30 \mathrm{ml} /$ hari dan kehilangan zat besi $\pm 1,3 \mathrm{mg}$ per hari. ${ }^{4,11}$ Zat besi dibutuhkan tubuh karena berperan dalam perkembangan otak, sistem kekebalan tubuh, mielogenesis dan pemeliharaan mielin, berfungsi sebagai hantar rangsangan melalui sel saraf. $^{12,13}$ Kekurangan zat besi dapat menurunkan aktifitas monoamine oxidase. Aktifitas neurologikal berfungsi dalam sintesa dopamin dan serotonin. Dopamin dengan tirosin berfungsi dalam koordinasi motorik. Serotonin berguna untuk neurotransmiter dan pemusatan perhatian atau konsentrasi. ${ }^{14,15}$ Kadar zat besi yang rendah berdampak pada kinerja kognitif dan berpengaruh terhadap konsentrasi belajar. ${ }^{16,17}$

$$
\text { Anemia pada remaja putri }
$$

menurunkan konsentrasi belajar yang berdampak pada prestasi belajar. Kadar $\mathrm{Hb}$ yang tinggi dapat menunjukkan skor kecerdasan intelektual yang tinggi. ${ }^{18}$ Penelitian Astiandani (2015) menunjukkan anemia pada remaja putri berisiko 1,875 kali lipat memperoleh prestasi belajar yang rendah dibandingkan remaja putri yang tidak anemia. ${ }^{19}$ Penelitian Hasanah (2015) menunjukkan tingkat keparahan anemia yang tinggi berdampak pada rendahnya nilai biokimia yang diperoleh mahasiswa. ${ }^{20}$ Status anemia berhubungan signifikan dengan ratarata nilai UTS dan UAS mata pelajaran IPA dan Bahasa Indonesia. ${ }^{21}$

SMP Unggulan Bina Insani adalah salah satu sekolah di Surabaya yang siswinya memiliki status sosial ekonomi menengah kebawah. SMP ini juga merupakan sekolah binaan dari Puskesmas Pacarkeling, tetapi kegiatan kesehatan yang dilakukan masih sebatas penimbangan berat badan, pengukuran tinggi badan, pemberian tablet tambah darah, pemeriksaan mata dan konsultasi kesehatan. Pemeriksaan kadar $\mathrm{Hb}$ masih belum dilakukan sehingga siswi berkemungkinan mengalami anemia. Selain itu belum pernah ada penelitian mengenai anemia dengan prestasi belajar di SMP ini.

Berdasarkan latar belakang diatas, menjelaskan bahwa Surabaya merupakan salah satu kota yang memiliki jumlah prevalensi anemia remaja yang cukup tinggi. SMP Unggulan Bina Insani adalah salah satu sekolah menengah pertama di Surabaya yang berkemungkinan siswinya mengalami anemia yang akan berdampak pada prestasi belajar. Berdasarkan uraian tersebut maka diperlukan adanya penelitian untuk mengetahui hubungan anemia dengan prestasi belajar. Tujuan penelitian adalah menganalisis hubungan anemia dengan prestasi belajar siswi di SMP Unggulan Bina Insani. Penelitian ini diharapkan bermanfaat bagi responden sebagai bahan informasi pentingnya memperhatikan makanan yang beragam, berimbang dan bergizi untuk mencegah terjadinya anemia yang dapat berpengaruh pada prestasi belajar. Penelitian ini juga diharapkan bermanfaat bagi pihak sekolah, orang tua, dan pembaca sebagai bahan informasi, pengetahuan, meningkatkan wawasan mengenai anemia sehingga dapat membantu mencegah terjadinya anemia pada remaja putri.

\section{METODE}

Penelitian ini adalah penelitian observasional analitik dengan desain cross sectional. Penelitian ini merupakan bagian dari penelitian payung Sumarmi et al. (2017). ${ }^{22}$ Besar sampel yang dibutuhkan dalam penelitian ini sebanyak 56 siswi, diperoleh dari perhitungan rumus Lameshow dengan populasi sebanyak 69 siswi. Metode yang digunakan dalam pengambilan sampel penelitian ini adalah simple random sampling dengan cara undian. Variabel penelitian ini terdiri dari karakteristik orang tua, karakteristik siswi, pola menstruasi, status anemia, serta prestasi belajar.

Data yang diambil dalam penelitian ini adalah data primer dan data sekunder. Data 
primer diperoleh dengan wawancara melalui kuesioner yakni karakteristik orang tua dan siswi serta pola menstruasi. Karakteristik orang tua terdiri dari pendidikan dan pekerjaan ibu serta pendapatan keluarga. Karakteristik siswi terdiri dari umur dan uang saku. Data primer lainnya yakni kadar $\mathrm{Hb}$ didapat melalui pengambilan darah pada pembuluh darah vena sebanyak 5 cc yang dilakukan oleh laboran, kemudian dianalisis dengan menggunakan metode cyanmethemoglobin di Laboratorium Gizi Fakultas Kesehatan Masyarakat Universitas Airlangga. Pola menstruasi terdiri dari usia menarche, siklus dan lama menstruasi. Status anemia diperoleh dari hasil analisis kadar $\mathrm{Hb}$ responden $(<12 \mathrm{~g} / \mathrm{dl})$. Data sekunder yakni prestasi belajar melalui rata-rata jumlah nilai lima mata pelajaran yakni matematika, IPA,IPS, bahasa indonesia dan bahasa inggris selama dua semester yang diperoleh dari sekolah.

Status anemia pada penelitian ini dikategorikan menjadi anemia dan tidak anemia. Usia menarche dikategorikan menjadi $<12$ tahun dan $\geq 12$ tahun. ${ }^{23}$ Siklus mentsruasi dikategorikan menjadi teratur (25-28 hari) dan tidak teratur $\left(<\right.$ atau $>25-28$ hari). ${ }^{24}$ Lama menstruasi dikategorikan menjadi pendek $(<3$ hari), normal (3-8 hari), dan panjang ( $>8$ hari). ${ }^{25}$ Prestasi belajar dikategorikan menjadi sangat baik ( 86-100), baik (71-85), cukup (56$70)$, dan kurang $(\leq 55) .{ }^{26}$ Pendidikan orang tua dikategorikan menjadi SD, SMP, SMA, dan perguruan tinggi. Pekerjaan orang tua dikategorikan menjadi PNS, pegawai swasta, wirausaha, TNI/POLRI, buruh industri, buruh harian, tidak bekerja atau ibu rumah tangga. Penghasilan orang tua dikategorikan sesuai UMR kota Surabaya (< dan $\geq 3.296 .212,50$ ). Umur siswi dikategorikan menjadi 10-13 tahun dan 14-16 tahun. Uang saku siswi dikategorikan menjadi < Rp 5.000, Rp 5.000 sampai 10.000, dan > Rp 10.000. Hasil dari penelitian dianalisis menggunakan analisis univariat dan bivariat. Analisis univariat digunakan untuk melihat distribusi frekuensi karakteristik orang tua dan siswi, pola menstruasi, status anemia dan prestasi belajar. Analisis bivariat digunakan untuk mengetahui hubungan antara dua variabel yang diteliti, menggunakan uji korelasi eta dan chi square $(p \leq 0,05)$. Penelitian ini juga telah melalui proses uji laik etik yang telah dilaksanakan oleh Komisi Etik Penelitian Kesehatan Fakultas Kesehatan Masyarakat Universitas Airlangga Surabaya pada tanggal 20 Juli 2017 dengan nomor sertifikat etik 425KEPK.

\section{HASIL DAN PEMBAHASAN}

Karakteristik orang tua pada Tabel 1 menunjukkan bahwa pendidikan orang tua sebagian besar adalah tamat SMA $(57,1 \%)$ tamat SMP $(44,6 \%)$. Pekerjaan orang tua sebagian besar adalah pegawai swasta (39,3\%) dan lainnya (tidak bekerja/ibu rumah tangga) (50,0\%). Pendapatan keluarga pada Tabel 1 menunjukkan sebagian besar adalah dibawah UMR (69,6\%). Pendidikan adalah modal dasar untuk menunjang perekonomian, tingkat pendidikan yang tinggi dapat mempengaruhi penentuan dalam mendapatkan gizi yang baik menjadi meningkat. ${ }^{27}$ Peneltian Yamin (2012) menunjukkan ayah dan ibu dengan pendidikan rendah berpeluang 2,221 dan 1,945 kali remaja menderita anemia dibandingkan ayah dan ibu dengan pendidikan tinggi. ${ }^{28}$ Jenis pekerjaan orang tua berkaitan dengan pendapatan yang diperoleh sehingga mempengaruhi daya beli dan penyediaan makanan. ${ }^{29}$ Penelitian Siahaan (2012) dan Yamin (2012) menunjukkan ibu yang bekerja dan ayah dengan pekerjaan tidak tetap berpeluang 0,536 dan 2,535 kali remaja menderita anemia dibandingkan ibu yang tidak bekerja dan pekerjaan ayah yang tetap. $^{28,29}$ Pendapatan keluarga juga mempengaruhi daya beli, pendapatan yang cukup mempermudah dalam memenuhi segala kebutuhan. ${ }^{30}$ Pendapatan yang rendah menyebabkan pemenuhan kebutuhan terutama daya beli makanan menjadi rendah sehingga mempengaruhi status gizi dan kesehatan. ${ }^{27}$ 
Tabel 1.Distribusi Frekuensi Karakteristik

\begin{tabular}{|c|c|c|}
\hline \multicolumn{3}{|l|}{ Orang Tua } \\
\hline Karakteristik & $n$ & $\%$ \\
\hline \multicolumn{3}{|l|}{ Pendidikan Ibu } \\
\hline SD & 9 & 16,1 \\
\hline SMP & 25 & 44,6 \\
\hline SMA & 20 & 35,7 \\
\hline PT & 2 & 3,6 \\
\hline \multicolumn{3}{|l|}{ Pekerjaan Ibu } \\
\hline PNS & 1 & 1,8 \\
\hline Pegawai Swasta & 11 & 19,6 \\
\hline Wirausaha & 12 & 21,4 \\
\hline Buruh Industri & 2 & 3,6 \\
\hline Buruh Harian & 2 & 3,6 \\
\hline $\begin{array}{l}\text { Lainnya (Tidak bekerja atau ibu } \\
\text { rumah tangga) }\end{array}$ & 28 & 50,0 \\
\hline \multicolumn{3}{|l|}{ Pendidikan Ayah } \\
\hline SD & 4 & 7,1 \\
\hline SMP & 17 & 30,4 \\
\hline SMA & 32 & 57,1 \\
\hline PT & 3 & 5,4 \\
\hline \multicolumn{3}{|l|}{ Pekerjaan Ayah } \\
\hline PNS & 2 & 3,6 \\
\hline Pegawai Swasta & 22 & 39,3 \\
\hline Wirausaha & 16 & 28,6 \\
\hline TNI/POLRI & 2 & 3,6 \\
\hline Buruh Harian & 7 & 12,5 \\
\hline $\begin{array}{l}\text { Lainnya (Tidak bekerja atau } \\
\text { ibu rumah tangga) }\end{array}$ & 7 & 12,5 \\
\hline \multicolumn{3}{|l|}{ Pendapatan keluarga } \\
\hline$<$ UMR & 39 & 69,6 \\
\hline$\geq$ UMR & 17 & 30,4 \\
\hline Total & 56 & 100,0 \\
\hline
\end{tabular}

Tabel 2. Distribusi Frekuensi Karakteristik

\begin{tabular}{lcc}
\multicolumn{1}{c}{ Siswi } & & \\
\hline \multicolumn{1}{c}{ Karakteristik } & $\mathbf{n}$ & $\%$ \\
\hline Umur Siswi & & \\
$10-13$ tahun & 42 & 75,0 \\
$14-16$ tahun & 14 & 25,0 \\
\hline Uang Saku & & \\
$<5.000$ & 1 & 1,8 \\
$5.000-10.000$ & 43 & 76,8 \\
$>10.000$ & 12 & 21,4 \\
\hline Total & 56 & 100,0 \\
\hline
\end{tabular}

Karakteristik siswi pada Tabel 2 menunjukkan bahwa sebagian besar siswi berumur $10-13$ tahun sebanyak $75 \%$ dan $25 \%$ diantaranya berusia 14-16 tahun. Menurut
Tim Poltekkes Depkes Jakarta I (2010) usia remaja antara 10 sampai 19 tahun yang dibagi menjadi tiga golongan yakni masa remaja awal (10-13 tahun), masa remaja tengah (14-16 tahun) dan masa remaja akhir (17-19 tahun). ${ }^{9}$ Remaja adalah masa transisi dari anak-anak menjadi dewasa. ${ }^{31}$ Pada masa ini remaja memiliki keunikan gaya hidup sehingga berdampak pada masalah gizi yang dialami salah satunya anemia. ${ }^{2}$ Keunikan gaya hidup tesebut seperti pola makan kurang tepat untuk menjaga penanmpilan, kesukaan berlebihan pada makanan tertentu, menstruasi dan pemahaman gizi yang keliru. ${ }^{3}$

Karakteristik siswi pada Tabel 2 juga menunjukkan sebagian besar siswi memiliki uang saku antara $\operatorname{Rp} 5.000-10.000$ (76,8\%). Uang saku adalah uang pemberian orang tua yang digunakan untuk memenuhi keperluan anak seperti membeli jajan, minuman dan makanan di luar rumah (fast food), dan lain sebagainya. ${ }^{32,33}$ Pemberian uang saku yang berlebihan oleh orang tua dapat mempengaruhi kebiasaan jajan. ${ }^{34}$ Selain itu penelitian Pratiwi (2016) menunjukkan pemberian uang saku berhubungan dengan kejadian anemia. ${ }^{35}$ Uang saku yang rendah berpeluang 2,995 kali menderita anemia dibandingkan yang memiliki uang saku yang tinggi. ${ }^{35}$

Anemia adalah kadar hemoglobin dan hitung eritrosit serta hematokrit yang berada dibawah batas normal. ${ }^{36}$ Salah satu kelompok yang rentan menderita anemia adalah remaja putri. Remaja putri berisiko 1,55 kali mengalami anemia dibandingkan laki-laki. ${ }^{37}$ Pada Tabel 3 menunjukkan sebanyak 78,6\% siswi tidak mengalami anemia dan sebanyak $21,4 \%$ mengalami anemia. Rata-rata kadar $\mathrm{Hb}$ siswi adalah 13,22 g/dl. Kadar normal Hb pada remaja putri adalah $\geq 12 \mathrm{~g} / \mathrm{dll}^{36}$ Dapat disimpulkan bahwa pada penelitian ini ratarata kadar $\mathrm{Hb}$ siswi termasuk dalam normal. Anemia disebabkan oleh banyak faktor antara lain defisiensi zat gizi mikro dan vitamin, infeksi cacing tambang dan schistosomiasis, malaria, menstruasi dan genetik. ${ }^{9,10}$

Usia menarche pada Tabel 3 menunjukkan sebagian besar siswi memasuki masa menstruasi pada usia $\geq 12$ tahun $(73,2 \%)$. Usia menarche umumnya terjadi pada usia 12 sampai 16 tahun, tetapi sering 
terjadi pada usia 11 tahun..$^{23}$ Usia menarche dikatakan cepat bila terjadi pada usia kurang dari 11 tahun, normal terjadi antara usia 11 sampai 14 tahun, dan lambat bila terjadi pada usia lebih dari 14 tahun. ${ }^{38}$ Remaja putri pada penelitian ini tergolong memasuki usia menarche normal dengan rata-rata 11,86 tahun. Uji chi square pada Tabel 4 menunjukkan usia menarche tidak berhubungan dengan anemia $(p=0,189)$. Sebagian besar siswi mengalami usia menarche yang tergolong normal dan sebagian besar siswi tidak mengalami anemia. Anemia berkontribusi pada tertundanya usia menarche hingga 1,5 sampai 2 tahun dan respon imun menjadi terganggu. ${ }^{39,40}$ Hasil penelitian tersebut sependapat dengan penelitian Rupali dan Sanjay (2015) yang juga menunjukkan tidak ada hubungan antara usia menarche dengan anemia. ${ }^{40}$

Anemia dapat diderita oleh setiap kelompok umur. Anemia umumnya terjadi karena rendahnya kadar zat besi dalam tubuh. ${ }^{10}$ Menstruasi adalah salah satu penyebab kadar zat besi tubuh menjadi rendah. Kadar zat besi yang dibawah batas normal dalam waktu yang lama menyebabkan terjadinya anemia. ${ }^{10}$

Siklus menstruasi pada Tabel 3 menunjukkan sebanyak 58,9\% memiliki siklus yang teratur sedangkan sebanyak $41,1 \%$ memiliki siklus yang tidak teratur. Siklus normal menstruasi wanita mencapai 25 sampai 28 hari, tetapi pendapat lain mengemukakan berkisar antara 22-35 hari atau 21-40 hari. $^{23,24,41}$

Tabel 3.Distribusi Frekuensi Pola Menstruasi, Status Anemia, dan Prestasi Belajar

\begin{tabular}{|c|c|c|}
\hline Variabel & $\mathrm{n}$ & $\%$ \\
\hline \multicolumn{3}{|l|}{ Status } \\
\hline \multicolumn{3}{|l|}{ Anemia } \\
\hline Anemia & 12 & 21,4 \\
\hline Tidak & 44 & 78,6 \\
\hline Anemia & & \\
\hline \multicolumn{3}{|l|}{ Pola } \\
\hline \multicolumn{3}{|l|}{ Menstruasi } \\
\hline \multicolumn{3}{|l|}{ Usia } \\
\hline \multicolumn{3}{|l|}{ Menarche } \\
\hline$<12$ tahun & 15 & 26,8 \\
\hline$\geq 12$ tahun & 41 & 73,2 \\
\hline \multicolumn{3}{|l|}{ Siklus } \\
\hline \multicolumn{3}{|l|}{ Menstruasi } \\
\hline Teratur & 33 & 58,9 \\
\hline Tidak & 23 & 41,1 \\
\hline \multicolumn{3}{|l|}{ Teratur } \\
\hline \multicolumn{3}{|l|}{ Lama } \\
\hline \multicolumn{3}{|l|}{ Menstruasi } \\
\hline $\begin{array}{l}\text { Normal (3- } \\
8 \text { hari) }\end{array}$ & 53 & 94,6 \\
\hline $\begin{array}{l}\text { Panjang (> } \\
8 \text { hari) }\end{array}$ & 3 & 5,4 \\
\hline \multicolumn{3}{|l|}{ Prestasi } \\
\hline \multicolumn{3}{|l|}{ Belajar } \\
\hline Baik & 55 & 98,2 \\
\hline Cukup & 1 & 1,8 \\
\hline Total & 56 & 100,0 \\
\hline
\end{tabular}

Tabel 4. Hasil Tabulasi Silang Pola Menstruasi dengan Anemia Siswi di SMP Unggulan Bina Insani

\begin{tabular}{|c|c|c|c|c|c|c|c|}
\hline \multirow{3}{*}{ Pola Menstruasi } & \multicolumn{4}{|c|}{ Status Anemia } & \multirow{2}{*}{\multicolumn{2}{|c|}{ Total }} & \multirow{3}{*}{$p$ value } \\
\hline & \multicolumn{2}{|c|}{ Anemia } & \multicolumn{2}{|c|}{ Tidak Anemia } & & & \\
\hline & $\mathbf{n}$ & $\%$ & $\mathbf{n}$ & $\%$ & $n$ & $\%$ & \\
\hline \multicolumn{8}{|l|}{ Usia menarche } \\
\hline$<12$ tahun & 5 & 33,3 & 10 & 66,7 & 15 & 100,0 & 0,189 \\
\hline$\geq 12$ tahun & 7 & 17,1 & 34 & 82,9 & 41 & 100,0 & \\
\hline \multicolumn{8}{|l|}{ Siklus Menstruasi } \\
\hline Teratur & 8 & 24,2 & 25 & 75,8 & 33 & 100,0 & 0,539 \\
\hline Tidak Teratur & 4 & 17,4 & 19 & 82,6 & 23 & 100,0 & \\
\hline \multicolumn{8}{|l|}{ Lama Menstruasi } \\
\hline Normal ( $3-8$ hari) & 11 & 20,8 & 42 & 79,2 & 53 & 100,0 & \\
\hline Panjang ( $>8$ hari) & 1 & 33,3 & 2 & 66,7 & 3 & 100,0 & 0,046 \\
\hline
\end{tabular}


Uji statistik pada Tabel 4 menunjukkan siklus menstruasi tidak berhubungan dengan anemia $(p=0,539)$. Sebagian besar siswi memiliki siklus menstruasi yang teratur sehingga kemungkinan kehilangan zat besi tidak dalam jumlah banyak. Siswi yang memiliki siklus menstruasi teratur juga berkemungkinan memiliki pola makan yang baik dan mengkonsumsi tablet tambah darah yang telah diberikan oleh pihak puskesmas sehingga dapat mengganti zat besi yang hilang saat menstruasi berlangsung. Hasil penelitian tersebut sesuai dengan penelitian Yamin (2012) yang menunjukkan tidak terdapat hubungan antara siklus menstruasi dengan kejadian anemia dengan remaja putri. ${ }^{28}$

Menstruasi adalah salah satu penyebab anemia pada remaja putri. $^{10}$ Menstruasi adalah suatu pendarahan yang terjadi secara teratur akibat dari pelepasan sel telur dalam dinding rahim di setiap bulannya. ${ }^{23,41}$ Pendarahan menyebabkan zat besi dalam darah keluar dari tubuh. Zat besi berfungsi dalam proses eritropoiesis, metabolisme oksidatif dan respon imun seluler. ${ }^{42}$ Menurut Arisman remaja putri yang memiliki siklus menstruasi pendek dan cepat berkemungkinan kehilangan zat besi dalam jumlah banyak dan persediaan menjadi berkurang. ${ }^{43}$ Siklus menstruasi setiap wanita berbeda, perbedaan disebabkan oleh adanya faktor pengaruh seperti stres, hormon, dan aktivitas fisik. ${ }^{24}$

Lama mesntruasi siswi pada Tabel 3 menunjukkan sebanyak $94,6 \%$ memiliki lama menstruasi yang normal, sedangkan $5,4 \%$ diantaranya memiliki lama menstruasi yang panjang. Lama menstruasi wanita terjadi selama 8 hari dan tersingkat 1 hari. ${ }^{44}$ Berdasarkan hasil uji statistik (Tabel 4) menunjukkan bahwa lama menstruasi berhubungan dengan anemia $(p=0,046)$. Penelitian ini selaras dengan penelitian yang dilakukan di SMP Negeri 4 Banjarbaru, menunjukkan lama menstruasi berhubungan dengan kejadian anemia pada remaja putri. ${ }^{45}$

Lama menstruasi adalah panjang hari saat darah menstruasi keluar dari tubuh. Panjang hari mesntruasi yang berlangsung semakin lama memungkinkan zat besi keluar dari tubuh semakin meningkat. ${ }^{46}$ Kehilangan zat besi karena menstruasi menyebabkan keseimbangan zat besi tubuh terganggu. Zat besi yang rendah menyebabkan pembentukan sel darah merah terganggu sehingga terjadi anemia. ${ }^{15}$ Remaja putri dengan lama menstruasi tidak normal berpeluang 2,008 kali menderita anemia. ${ }^{28}$

Prestasi belajar pada Tabel 3 menunjukkan prestasi belajar siswi sebagian besar adalah baik, yakni sebanyak $96,4 \%$ dan lainnya memiliki prestasi belajar yang cukup $(1,8 \%)$. Prestasi belajar adalah penguasaan pengetahuan, ketrampilan, dikembangkan melalui mata pelajaran dan ditunjukkan dengan nilai. ${ }^{47}$ Rata-rata prestasi belajar pada penelitian ini adalah 78,6411, tergolong dalam capaian yang baik. ${ }^{26}$ Tabel 5 menunjukkan bahwa terdapat hubungan antara anemia dengan prestasi belajar siswi di SMP Unggulan Bina Insani Surabaya $(p=0,026)$. Hasil tersebut sesuai dengan penelitian lain yang menunjukkan adanya hubungan bermakna antara anemia dengan hasil belajar siswi. ${ }^{48}$

Kadar hemoglobin adalah salah satu indikator penentu anemia. ${ }^{49}$ Rendahnya kadar hemoglobin salah satunya disebabkan oleh menstruasi yang terjadi setiap bulan. ${ }^{9,49}$ Menstruasi menyebabkan darah yang mengandung zat besi keluar dari tubuh. Defisiensi zat besi menyebabkan

Tabel 5. Hasil Tabulasi Silang Anemia dengan Presatasi Belajar Siswi di SMP Unggulan Bina Insani

\begin{tabular}{lccccccc}
\hline \multirow{2}{*}{ Status Anemia } & \multicolumn{4}{c}{ Prestasi Belajar } & \multicolumn{2}{c}{ Total } & \multirow{2}{*}{$\boldsymbol{p}$ value } \\
\cline { 2 - 6 } & \multicolumn{3}{c}{ Baik } & \multicolumn{2}{c}{ Cukup } & \multicolumn{2}{c}{} \\
\cline { 2 - 7 } & $\mathbf{n}$ & $\%$ & $\mathbf{n}$ & $\%$ & $\mathbf{n}$ & $\%$ & \\
\hline Anemia & 12 & 21,8 & 0 & 0,0 & 12 & 21,4 & \multirow{2}{*}{0,026} \\
Tidak Anemia & 43 & 78,2 & 1 & 100,0 & 44 & 78,6 & \\
\hline
\end{tabular}


koordinasi motorik terganggu dan pemusatan perhatian atau konsentrasi menjadi menurun. ${ }^{15}$ Anemia yang terjadi pada remaja berdampak pada terhambatnya mental dan kecerdasan serta menurunnya konsentrasi dan semangat belajar., ${ }^{3,17}$ Rendahnya daya konsentrasi berpengaruh pada fokus siswa salam menerima dan memahami mata pelajaran yang dapat berdampak pada hasil belajar. Selain anemia, faktor yang dapat mempengaruhi prestasi belajar adalah intelegensi, motivasi belajar dan gaya belajar. $^{50,51}$

\section{KESIMPULAN}

Sebagian besar remaja putri pada penelitian ini memasuki masa menstruasi pada usia $\geq 12$ tahun, memiliki siklus menstruasi teratur, dan lama menstruasi yang normal. Terdapat hubungan antara lama menstruasi dengan anemia. Semakin lama menstruasi berlangsung maka kemungkinan kehilangan zat besi meningkat dan menderita anemia. Remaja putri dalam penelitian ini sebagian besar tidak mengalami anemia dan memiliki prestasi belajar yang baik. Terdapat hubungan antara anemia dengan prestasi belajar remaja putri. Anemia menyebabkan daya konsentrasi rendah dan berdampak pada prestasi belajar menjadi kurang optimal atau rendah. Kelemahan dalam penelitian ini adalah faktor lain yang mempengaruhi anemia (seperti pola makan atau asupan zat gizi, kebiasaan sarapan dan konsumsi teh, pengetahuan, penyakit infeksi), pola mentruasi (seperti stres, aktifitas fisik, volume menstruasi) dan prestasi belajar (seperti motivasi dan cara belajar, lingkungan, kecerdasan (IQ), dan lainnya) tidak diteliti atau dijadikan variabel penelitian.

\section{REFERENSI}

1. Wahyuningsih $U$, Khomsan A, Ekawidyani KR. Asupan Zat Gizi, Status Gizi, dan Status Anemia pada Remaja Laki-laki Pengguna Narkoba di Lembaga Pemasyarakatan Anak Pria Tangerang. Jurnal Gizi dan Pangan 2014;9(1):23-28.
2. Soetjiningsih. Tumbuh Kembang Remaja dan Permasalahannya. Cetakan ke 3. Jakarta: Sagung Seto; 2010.

3. Adriani M, Wirjatmadi B. Peranan Gizi dalam Siklus Kehidupan. Jakarta: Kencana; 2014.

4. Citrakesumasari. Anemia Gizi, Masalah dan Pencegahannya. Yogyakarta: Kalika; 2012.

5. Balitbangkes RI. Riset Kesehatan Dasar 2013. Jakarta: Kesehatan Kementrian Kesehatan RI. 2013. Availableat: Laporan_riskesdas_2013_final.pdf. Diakses pada tanggal 4 Oktober 2016.

6. Dinkes Provinsi Jawa Timur. Profil Kesehatan Provinsi Jawa Timur, tahun $2010 . \quad$ Availableat: http://dinkes.jatimprov.go.id/userfile/doku men/1312948638_Profil_Kesehatan_Provi nsi_Jawa_Timur_2010.pdf. Diakses pada tanggal 13 Februari 2017.

7. Dinkes Kota Surabaya. Jaring Kesehatan Mental Emosional Siswa-Siswi. 2011. Availableat:

dinkes.surabaya.go.id/portal/index.php/be rita/jaring-kesehatan-mental-emosional-

siswa-siswi. Diakses pada tanggal 13 Oktober 2016.

8. Setyono FS. Hubungan Tingkat Pengetahuan Gizi, Body Image, dan Tindakan Diet dengan Status Anemia dan Status Gizi Remaja Putri. Skripsi. Surabaya: Universitas Airlangga, 2010.

9. Tim Penulis Poltekkes Depkes Jakarta I. Kesehatan Remaja Problem dan Solusinya. Jakarta: Salemba Medika; 2010.

10.WHO. Assessing The Iron Status of Population: Including Literature Reviewss. $2^{\text {nd }}$ ed. Switzerland: Department of Nutrition for Health and Development (NHD); 2004.

11. Hidayat N, Sunarti S. Validitas Pemeriksaan Kadar Hemoglobin Menggunakan Metode $\mathrm{Hb}$ Meter pada Remaja Putri di MAN Wonosari. Kesmas 2015;9(1):11-18.

12.Insel P, Turner RE, Ross D. Discovering Nutrition. $3^{\text {rd }}$ ed. Canada: Jones and Bartlett; 2010.

13.Irsa L. Gangguan Kognitif pada Anemia Defisiensi Besi. Sari Pediatri 2002;4(3):114118. 
14.Pusponegoro HD. Peran Serotonin pada Anak dengan Gangguan Autistik. Sari Pediatri 2007; 8(4):115-119.

15.Gurnida DA. Revolusi Kecerdasan: Nutrisi bagi Perkembangan Otak. 2011. Availableat:

http://repository.unpad.ac.id/17662/1/Pus taka_Unpad_Revolusi_-Kecerdasan.pdf.

Diakses pada tanggal 24 April 2017.

16.Sharman A. Anemia Testing in PopulationBased Surveys: General Information and Guidelines for Country Monitors and Program Managers. Calverton, Maryland USA: ORC Macro; 2000.

17.Ahmady, Hapzah, dan Mariana D. Penyuluhan Gizi dan Pemberian Tablet Besi terhadap Pengetahuan dan Kadar Hemoglobin Siswi Sekolah Menengah Atas Negeri di Mamuju. Jurnal Kesehatan Manarang 2016;2(1):15-20.

18.Kusmiyati Y, Meilani N, Ismail S. Kadar Hemoglobin dan Kecerdasan Intelektual Anak. Jurnal Kesehatan Masyarakat 2013;8(3):115-118.

19.Astiandani A. Hubungan Kejadian Anemia dengan Prestasi Belajar Matematika pada Remaja Putri Kelas 11 di SMAN 1 Sedayu. Skripsi. Yogyakarta: Sekolah Tinggi Ilmu Kesehatan 'Aisyiyah, 2015.

20. Hasanah U. Hubungan Anemia Defesiensi Zat Gizi Besi dengan Hasil Belajar Biokimia Mahasiswa Biologi FMIPA Unimed Tahun 2014. Jurnal Keluarga Sehat Sejahtera 2015;13(25):29-36.

21. Heryati L, Setiawan B. Kegemukan, Anemia, dan Prestasi Belajar Siswa Sekolah Dasar di Kota Bogor. J. Gizi Pangan 2014;9(3):3159166.

22.Sumarmi S, Nindya TS, Diana R, Rifqi MA. Kadar Serum Hepcidin dan TNFa pada Remaja Obesitas sebagai Biomarker Defisiensi Zat Besi yang Dipicu oleh Diet Tinggi Lemak. Laporan Penelitian. Surabaya: Universitas Airlangga, 2017.

23.Warianto C. Daur Menstruasi. 2011. Availableat:

http://skp.unair.ac.id/repository/GuruIndonesia/DaurMesntruasi_ChaidarWarian to_21.pdf. Diakses pada tanggal 1 Januari 2017.

24.Ramdhani A. Women's Health. Bandung: Leaf Production; 2010.
25. Narulita AE. Hubungan Lama Menstruasi dan Siklus Menstruasi dengan Perubahan Kadar Hemoglobin Siswi Kelas II SMK YPM 11 Wonoayu Sidoarjo. Skripsi. Surabaya: Universitas Airlangga, 2012.

26. Kemendikbud RI. Panduan Penilaian untuk Sekolah Menengah Pertama (SMP). Jakarta: Direktorat Jenderal Pendidikan Dasar dan Menengah; 2015.

27. Mariza A. Hubungan Pendidikan dan Sosial Ekonomi dengan Kejadian Anemia pada Ibu Hamil di BPS T Yohan Way Halim Bandar Lampung Tahun 2015. Jurnal Kesehatan Holistik 2016;10(1):5-8.

28.Yamin T. Hubungan Pengetahuan, Asupan Gizi dan Faktor Lain yang Berhubungan dengan Kejadian Anemia pada Remaja Putri di SMA Kabupaten Kepulauan Selayar Tahun 2012. Skripsi. Depok: Universitas Indonesia, 2012.

29.Siahaan NR. Faktor-faktor yang Berhubungan dengan Status Anemia pada Remaja Putri di Wilayah Kota Depok Tahun 2011 (Analisis Data Sekunder Survei Anemia Remaja Putri Dinas Kesehatan Kota Depok Tahun 2011). Skripsi. Depok: Universitas Indonesia, 2012.

30.Djafar F. Pengaruh Kondisi Sosial Ekonomi Orang Tua Terhadap Motivasi Belajar Anak. Jurnal Manajemen Pendidikan Islam 2014;2(1):1-13.

31.Erpridawati DD. Hubungan Pengetahuan Tentang Gizi dengan Status Gizi Siswa SMP di Kecamatan Kerjo Kabupaten Karanganyar. Skripsi. Solo: Universitas Muhammadiyah Surakarta, 2012.

32.Muwakhidah, Tri D. Faktor Risiko yang Berhubungan dengan Obesitas pada Remaja. Jurnal Kesehatan 2008;I(2):133140.

33. Rosyidah Z, Andrias DR. Jumlah Uang Saku dan Kebiasaan Melewatkan Sarapan Berhubungan dengan Status Gizi Lebih Anak Sekolah Dasar. Media Gizi Indonesia 2015;10(1):1-6.

34.Laenggeng $\mathrm{AH}$, Lumalang $\mathrm{Y}$. Hubungan Pengetahuan Gizi dan Sikap Memilih Makanan Jajanan dengan Status Gizi Siswa SMP Negeri 1 Palu. Jurnal Kesehatan Tadulako 2015;1(1):49-57.

35.Pratiwi E. Faktor-faktor yang Mempengaruhi Anemia pada Siswi MTS 
Ciwandan. Skripsi. Jakarta: Universitas Islam Negeri Syarif Hidayatullah, 2016.

36. Handayani W, Haribowo AD. Buku Ajar Asuhan Keperawatan pada Klien dengan Gangguan Sistem Hematologi. Jakarta: Salemba Medika; 2008.

37.Latifah L, Setyani A, Nurcahyani YD. Anemia, Prestasi, dan Kecerdasan pada Remaja Awal Laki-laki dan Perempuan. MGMI 2015;7(1):45-56.

38.Elmart FCC. Mahir Menjaga Organ Intim Wanita. Solo: Tinta Medina; 2012.

39.Verma A, Rawal VS, Kedia A, Kumar D, Chauhan J. Factors Influencing Anaemia Among Girls of School Going Age (6-18 Years) from The Slums of Ahmedabad City. Indian Journal of Community Medicine 2004;29(1):25-26.

40.Rupali P, Sanjay K. Anemia: Does it Have Effect on Menstruation?. Scholars Journal of Applied Medical Sciences (SJAMS) 2015;3(1G):514-517.

41.Kusmiran E. Kesehatan Reproduksi Remaja dan Wanita. Jakarta: Salemba Medika; 2011.

42.Perdana WY, Jacobus DY. Hepcidin dan Anemia Defisiensi Besi. CDK 2015;42(12):919-926.

43.Arisman MB. Gizi Dalam Daur Kehidupan. Edisi 2. Penerbit Buku Kedokteran Jakarta: EGC; 2010.

44.Ganong WF. Buku Ajar Fisiologi Kedokteran. Edisi 22. Penerbit Buku Kedokteran Jakarta: EGC; 2008.

45. Basith A, Agustina R, Diani N. Faktor-faktor yang Berhubungan dengan Kejadian
Anemia pada Remaja Putri. Dunia Keperawatan 2017;5(1):1-10.

46.Sirait AL. Hubungan Tingkat Konsumsi Zat Besi dan Pola Menstruasi dengan Kejadian Anemia pada Remaja Putri di SMP Kristen 1 Surakarta. Skripsi. Solo: Universitas Muhammadiyah Surakarta, 2015.

47.Kemendikbud. Kamus Besar Bahasa Indonesia Daring. Badan Pengembangan dan Pembinaan Bahasa. 2016. Availableat: https://kbbi.kemdikbud.go.id. Diakses pada tanggal 11 Mei 2017.

48.Mulyadi, Lolong JJS, Labenjang ER. Hubungan Antara Anemia dengan Hasil Belajar Siswi SMP Negeri 3 Sapa Kecamatan Tenga Kabupaten Minahasa Selatan. Jurnal Keperawatan 2014;2(2):1-7.

49.WHO. Haemoglobin concentrations for the diagnosis of anaemia and assessment of severity. Switzerland: Department of Nutrition for Health and Development (NHD); 2011.

50.Arini NKS. Pengaruh Tingkat Intelegensi dan Motivasi Belajar Terhadap Prestasi Akademik Siswa Kelas II SMA Negeri 99 Jakarta. 2012. Jurnal Psikologi, [e-journal]. Availableat:

http://publication.gunadarma.ac.id/bitstre am/123456789/1938/1/Artikel_10504121. pdf.

51.Darmawati J. Pengaruh Motivasi Belajar dan Gaya Belajar Terhadap Prestasi Belajar Ekonomi Siswa SMA Negeri di Kota Tuban. Jurnal Ekonomi Pendidikan dan Kewirausahaan 2013;1(1):79-90. 